\title{
Research on the Complex Mechanism of Placeness, Sense of Place, and Satisfaction of Historical and Cultural Blocks in Beijing's Old City Based on Structural Equation Model
}

\author{
Jing Zhang $\mathbb{D}^{1,2}$ and Qiang $L i \mathbb{D}^{1}$ \\ ${ }^{1}$ Faculty of Architecture, Civil and Transportation Engineering, Beijing University of Technology, Beijing 1001241, China \\ ${ }^{2}$ Department of Tourism Management, School of Landscape Architecture, Beijing University of Agriculture, Beijing 102206, China \\ Correspondence should be addressed to Qiang Li; liqiang@bjut.edu.cn
}

Received 24 December 2020; Accepted 27 May 2021; Published 5 July 2021

Academic Editor: Xueyong Liu

Copyright (c) 2021 Jing Zhang and Qiang Li. This is an open access article distributed under the Creative Commons Attribution License, which permits unrestricted use, distribution, and reproduction in any medium, provided the original work is properly cited.

\begin{abstract}
Using a structural equation model, this study explores the complex influence mechanism between the place experience and satisfaction of the historical and cultural blocks in the old city of Beijing and the mechanism differences between different types. Based on the data obtained in the questionnaire survey, this study uses the structural equation model method to propose a theoretical model of the relationship between place experience and satisfaction, and through path analysis, the theoretical model of the path relationship between the dimensions of placeness, sense of place, and satisfaction is estimated and tested. Through the mathematical verification of the structural model, on the basis of establishing the final theoretical model, the hypothesis to be proved is further verified. This study also uses the bootstrap method to test the significance of the mediating effect of place experience and uses multiple-group analysis to try to explore the moderating role of residents' and tourists' identity types in the model. The study found that there are multiple correlations among placeness, sense of place, and place satisfaction in the historical and cultural blocks in the old city of Beijing. The placeness is the foundation and the sense of place is the intermediary variable, which both affect satisfaction; furthermore, tourists and residents have differences in the mechanism of placeness and sense of place on satisfaction. On the one hand, the perception of placeness directly affects satisfaction, and on the other hand, the sense of place has an indirect effect on satisfaction. The positive effects of tourists' placeness on sense of place and sense of place on satisfaction are greater than that of residents. However, the positive effect of residents' placeness on satisfaction is greater than that of tourists.
\end{abstract}

\section{Introduction}

Place experience is the process of interaction and construction between people as a subject and the place as an object. Existing domestic and foreign related studies have proved that place experience has been studied from multiple angles, but it mainly contains two aspects. One is the research of people's cognition of place environmental elements, or the study of placeness; the second is the study of the emotional relationship between people and place, or the study of the sense of place. At the same time, studies have shown that environmental satisfaction is indeed closely related to relevant place experience [1]. However, the existing problems in related studies at home and abroad are as follows. First of all, the study on place experience, in terms of study content, either focuses on the attribute of placeness or the sense of place, and the study on place experience lacks completeness. Moreover, existing study perspectives generally start from place users (such as residents, immigrants, real estate owners, tourists, recreationists, and tourism operators, resp.), focusing on one of them. It is rare to conduct simultaneous surveys on residents and tourists, which brings about one-sidedness in the study content and study results. Secondly, the relationship between environmental satisfaction and place experience has no consistent results. In addition, as the most unique areas in the city, the 
historical and cultural blocks are not only the material carrier of the history and culture of the place, but also a lively stage of social life. This is a collection of place complex subjects and rich connotations. The contradiction between its protection and development has always been a hot topic for many scholars. However, at present, there are still few comprehensive researches from the multiple subjects of residents and tourists, as well as the multiple dimensions of placeness, sense of place, and satisfaction.

Beijing is an ancient capital with a history of more than 3,000 years. Since the early years of the Western Zhou Dynasty (c.11th century-711 BC), there have been many relics left around the city, especially the 33 historical and cultural blocks distributed in the old city as the most representative. However, in recent years, the placeness of historical and cultural blocks in the old city of Beijing has suffered a greater impact driven by globalization and modernity, and these blocks are facing place restructuring in the process of protection and development. Therefore, this article intends to conduct a multidimensional and multisubject survey and analysis of the place experience in these blocks in the old city of Beijing, tries to portray place experience from both placeness and sense of place, and explores its complex relationship with the survey subject's 20 satisfaction. At the same time, through group analysis, the mechanism differences of the model in different subjects are further revealed, to provide guidance and reference for the targeted protection and renewal of the historical and cultural blocks in the old city of Beijing.

\section{Definition of Related Concepts}

At present, there is no clear definition of place experience in the academic circle. It involves two dimensions: placeness and sense of place. Tuan [2] earlier proposed that place experience is closely related to the place. The related concepts have gradually deepened from place [2-4] to placeness $[3,5,6]$ and sense of place [7-11]. The sense of place has derived place dependence, place attachment, and place identity [12-21]. These three concepts are often mixed whether in empirical or theoretical research. Each concept may involve other concepts [22]. Lalli [23] thinks that place identity is the main concept and place attachment is a subset of it. Place attachment is widely considered as a synonym for sense of place, and place identity and place dependence are its two subconcepts $[14,15]$ in the research of environmental psychology.

Placeness refers to the physical environmental elements of a place and people's cognition of them [24]. It is the quality of coming from a place, or placeness [25]. Sense of place refers to people's emotional response to place and the emotional relationship between them [6-8], and it is people's overall perception of local environment. From the perspective of the man-land relationship, placeness is more from the perspective of "place" of the object, and the sense of place is more from the perspective of "man" of the subject.

This paper divides the place experience of historical and cultural blocks into two dimensions: placeness and sense of place. The placeness of these blocks is defined as local elements and people's cognition of local elements. The local elements of these blocks refer to relevant studies [26-33], mainly including elements of natural environment, elements of historical and cultural value, elements of architecture and space, and local service elements. The sense of place of these blocks is defined as people's overall perception of these blocks and the emotional connection with these blocks. Based on the classical theoretical framework of place attachment proposed by Williams $[14,15]$ and the dimensional research on sense of place by some scholars $[11,34-38]$, this paper divides the sense of place into three dimensions: place dependence, place attachment, and place identity. Place dependence emphasizes people's functional attachment to place; place attachment emphasizes the emotional connection between people and place; and place identity emphasizes the relationship between people and place, which is the dimension of people and place's related identities (Figure 1).

\section{Literature Review}

Place experience research since the 1990s has focused on the relationship among placeness, sense of place, and satisfaction. Its research methods have gradually expanded from qualitative analysis to principal component analysis, regression analysis, structural equation modeling, and other quantitative research. The research mainly focuses on the following three aspects:

First, the correlation between sense of place and satisfaction: Some researches in the field of tourism have confirmed that the sense of place positively affects satisfaction. If tourists have a stronger sense of identity with the destination, they are more likely to evaluate the destination positively, or the emotion between people and places plays an important role in the formation of tourist satisfaction [39-43]. In the field of residential satisfaction research, some scholars believe that identifying with a place will lead to positive evaluation and attitude towards the place $[20,23,44,45]$, or the sense of place has a positive impact on residential satisfaction [46-49]. However, some scholars believe that satisfaction is an influencing factor of place identity, and satisfaction tends to identify [50-52].

Second, the correlation between placeness (objective attribute of place or environment) and satisfaction: In the study on residents, some scholars think that residential satisfaction is a complex phenomenon, which depends on a series of factors. Residents' cognition of community is based on physical [53, 54], social [54-56], and personal factors $[47,57]$, which are intertwined and affect residents' satisfaction [58]. Amerigo and Aragones [59] constructed a theoretical model of residential satisfaction based on the interaction between the objective attributes of the environment and people through qualitative analysis. The model reveals three paths of the objective attribute of environment affecting residential satisfaction: directly acting on residential satisfaction; turning into subjective after the valuator's evaluation and resulting in a certain degree of satisfaction; and filtering the objective attributes through individual personality characteristics, thus affecting 


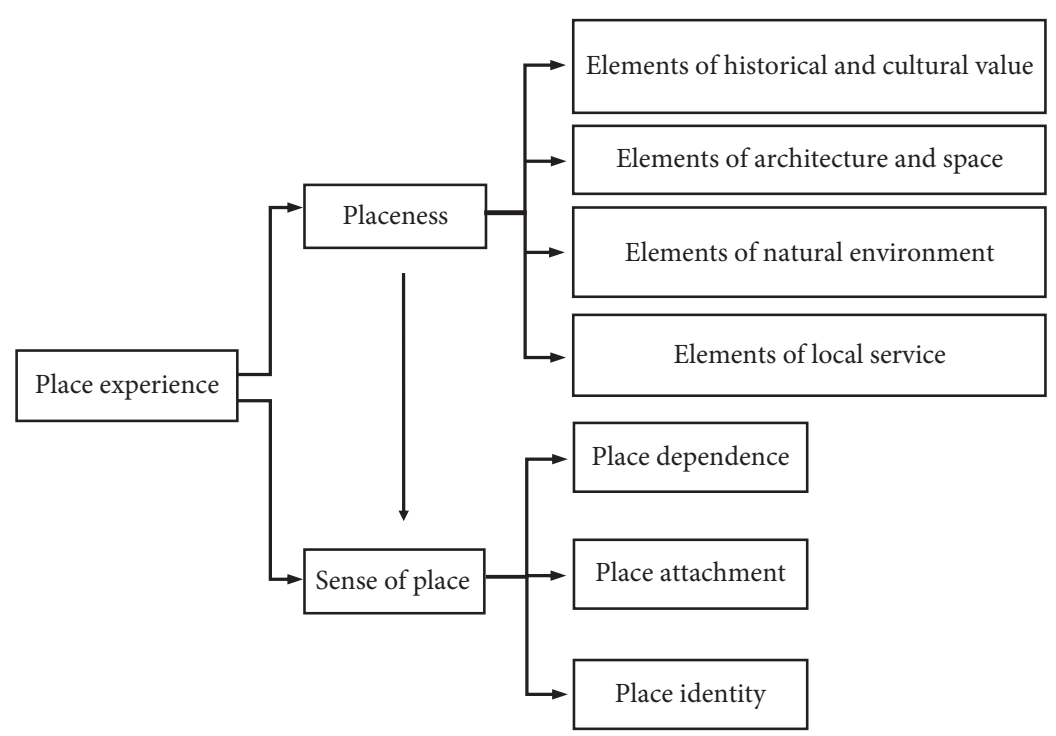

Figure 1: Conceptual map of place experience in historic and cultural blocks.

residents' satisfaction. However, some scholars believe that the objective characteristics of the place do not determine the satisfaction, but also refer to the subjective interpretation of these objective characteristics [45, 60-64]. In the research on tourists, some scholars $[25,65]$ have also proved that some local factors of tourist destinations have a significant positive impact on tourists' satisfaction through quantitative analysis methods.

Third, the relationship between placeness and sense of place: Some scholars have established conceptual models of the relationship between placeness and sense of place. They think that sense of place is the reaction of people stimulated by environmental factors such as material environment, social environment $[3,8,9]$, natural environment, and management environment [10], or placeness is the key factor to form sense of place. Other scholars have studied the relationship between placeness and sense of place through empirical analysis. Wardhani and Kusumowidagdo [32] used qualitative interviews to reveal the influence of physical factors on the formation of place sense. Özkan and Yilmaz [33] used regression analysis to verify that there is a significant positive correlation between environmental attributes of open space and place dependence. Zhang and Duan [29], Kyle et al. [66], and Tang [67] used structural equation models to verify the causal relationship between tourists' or residents' placeness and sense of place.

According to the review, relevant studies have proved that there are correlations between sense of place and satisfaction, placeness and satisfaction, and placeness and sense of place, but there is no consistent conclusion on the causal relationship among them. What is more, there are few studies on the mechanism of action among placeness, sense of place, and satisfaction. Besides, the existing researches only start from residents or tourists unilaterally, which are also one-sided. Taking the historical and cultural blocks in Beijing's old city as the research object, this paper attempts to explore the causal relationship and influencing mechanism among placeness, sense of place, and satisfaction from the perspective of residents and tourists.

\section{Theoretical Model and Data Collection}

4.1. Construction of the Proposed Model. Based on the review of relevant research at home and abroad, this study finally determined three variables of placeness, sense of place, and satisfaction (Figure 2), and the following hypotheses were proposed: H1: placeness has a significant positive impact on the sense of place; H2: placeness has a significant positive impact on satisfaction; H3: sense of place has a significant positive impact on satisfaction; H4: sense of place has a significant mediating effect on the relationship between placeness and satisfaction; and H5: when identity type is used as a moderating variable, the correlation strength between variables will change significantly.

4.2. Research Design and Data Collection. The study uses a combination of structured questionnaire surveys and observation interviews to obtain basic sample data. The content of the questionnaire consists of four parts: a measurement table of placeness and sense of place (Table 1), satisfaction, and demographic characteristics. Moreover, this study is formed on the basis of soliciting the opinions of relevant experts, using the five-point Likert scale method, with "strongly disagree-strongly agree" or "Very dissatisfied-very satisfied" corresponding to an evaluation scale of 1 to 5 points. Among them, the scale of placeness and sense of place is based on relevant research and has been modified as necessary to adapt to the current survey. Therefore, exploratory factor analysis (EFA) was conducted on the placeness scale and the sense of place scale by principal component analysis, and the observed variables $X_{18}, X_{22}$, $X_{12}, X_{13}$, and $Y_{8}$ were deleted on this basis. The investigation time was from September 25, 2017, to October 6, 2017, and from March 26, 2018, to April 6, 2018, the survey was 


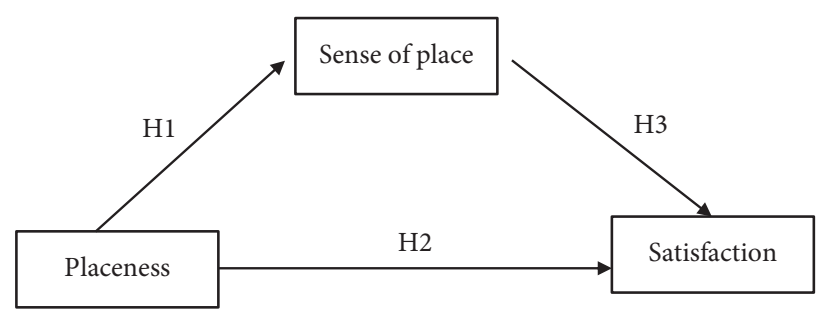

FIGURE 2: Hypothesis structure relationship model.

TABLE 1: Measurement index system.

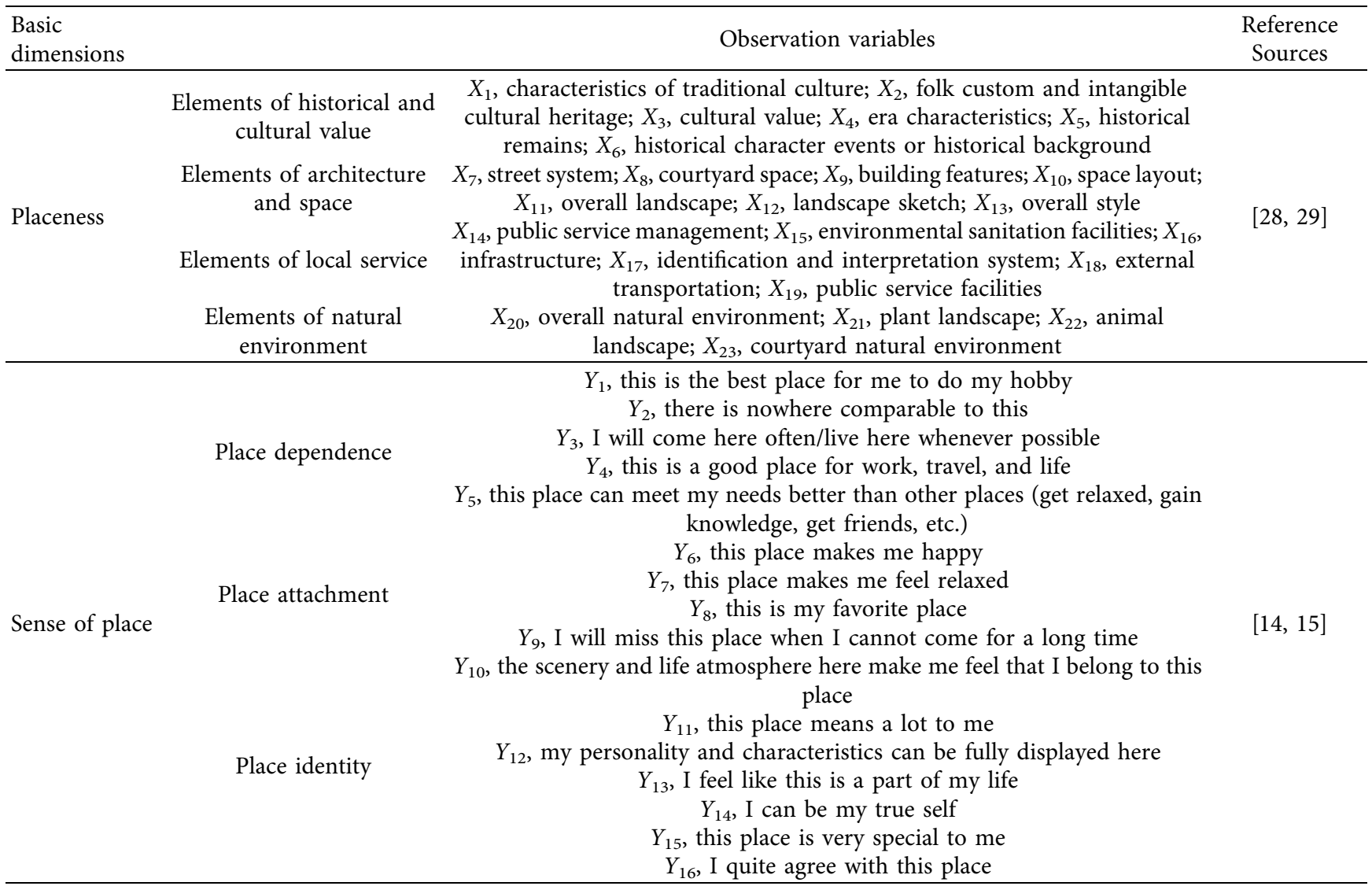

conducted in Dashilan, Nanluoguxiang, Fuchengmen Inner Street, and Dongsi North Santiao to Batiao in the historical and cultural districts of Beijing's old city. And the random sampling surveys of tourists on the streets and random household surveys are conducted on residents. The survey actually distributed 1,300 questionnaires, of which 1,224 were recovered, with a recovery rate of $94.15 \%$. Excluding 87 invalid questionnaires, 1137 valid questionnaires were finally obtained, with an effective rate of $92.89 \%$. Among them, a total of 563 questionnaires were returned by tourists and 574 questionnaires were returned by residents. SPSS 22.0 statistical software was used to process the sample data for the recovered data and combined with the use of AMOS 22.0 for structural equation model verification analysis.
4.3. Construction of Structural Model. The causal relationship model between placeness, sense of place, and satisfaction constructed in this study includes two latent variables of placeness, sense of place, and one observed variable of satisfaction. According to the results of exploratory factor analysis, the observed variables of placeness and sense of place are represented by the arithmetic mean of the scores of the items contained in each factor by the internal consistency approach of item packaging. Therefore, the observed variables of latent variable of placeness include elements of historical and cultural value, elements of architecture and space, elements of natural environment, and local service elements; the observed variables of latent variable of sense of place include place dependence, place attachment, and place identity. 


\section{Validation Analysis of Empirical Results}

5.1. Structural Characteristics of the Sample. The proportion of female tourists $(58.1 \%)$ is slightly higher than that of males (41.9\%). The age distribution is dominated by young and middle-aged under 44 , with a cumulative percentage of $80.5 \%$; among them, young people under 34 account for $62.2 \%$. Their occupations are widely distributed, with a relatively large proportion of students, accounting for $30.4 \%$, followed by business/service personnel and enterprise and institution management personnel, accounting for $15.2 \%$ and $14 \%$, respectively. The average monthly income is not high, and those with a monthly income of less than 10,000 yuan or a low-income group (including current students) account for 91.6\%. Highly educated people, with a college degree or above, account for $83.9 \%$. The source of tourists is mainly domestic, with tourists from other provinces accounting for $55.7 \%$ and local tourists from Beijing accounting for $41.2 \%$. The degree of involvement of tourists was not high before they came, and the percentage of tourists who did not understand and only knew a little reached $69.9 \%$. The proportion of first-time visitors and revisiting tourists is the same, and the proportion of tourists who visit twice or more is $55.2 \%$. Sightseeing and leisure and entertainment are the main motives for traveling, accounting for $79.5 \%$ of the total. Tourists stay mainly within half a day, with a cumulative percentage of $89.6 \%$.

The proportion of female residents (55.7\%) is slightly higher than that of men $(44.3 \%)$. The age distribution is dominated by middle-aged and elderly people over 45 years old. The cumulative proportion of people over 45 years old accounts for $82.1 \%$; among them, the proportion of people over 55 years old reaches $63.2 \%$. The occupation distribution is dominated by retirees, with a proportion of $68.9 \%$, followed by business/service personnel with a proportion of $14.2 \%$. The average monthly income is low, and those with a monthly income of less than 5,000 yuan (excluding current students) account for $89.2 \%$. The education level is not high, and the accumulative proportion of college degrees (excluding colleges) is $77.8 \%$. The main types of residents are aboriginals, with a total of $77.8 \%$ of people living for more than 20 years, followed by new immigrants, with $14.2 \%$ of people living for less than 5 years. The type of property ownership is mainly public rental housing, which accounts for $67.9 \%$ of the total, while people with private property rights and those who rent property rights to others each account for $16 \%$.

5.2. Reliability and Validity Testing of the Scale. Use SPSS 22.0 statistical software to calculate the Cronbach $\alpha$ of latent variables such as elements of historical and cultural value, elements of architecture and space, local service elements, natural environment elements, place dependence, place attachment, and place identity. The results show (Table 2) that the Cronbach $\alpha$ of the above latent variables is between 0.737 and 0.934 , which has good internal consistency and stability.
The comprehensive reliability (CR) of each scale is greater than 0.7 , and the average variance extracted (AVE) is greater than 0.5 , indicating that the scale has good internal reliability and discriminant validity.

\subsection{Inspection and Evaluation of the Measurement Model}

5.3.1. Testing of the Measurement Model. Using AMOS22.0 to test the degree of fit of the measurement model, the study obtains the index value of the degree of fit, shown in Table 3 . It can be seen from Table 3 that the RMSEA (0.082) in the absolute fitting index is slightly greater than 0.08 and the PGFI (0.452) in the simple fitting index is slightly less than 0.5 , which does not meet the fitting requirements; the other indicators meet the fitting requirements. It can be seen that the degree of fitting between the measurement model and the data are at a better level, the external quality of the model is good, and no further correction is needed.

5.3.2. Evaluation of the Measurement Model. Using the confirmatory factors to analyze and evaluate the measurement model, Table 4 lists the path coefficients of the measurement model; among them, the standardized coefficients are all above 0.6 and the standard deviations are all less than 0.1 , all of which have passed the significance test. The load value of the standardized factor of each measurement index in the latent variable is between 0.626 and 0.877 , which meets the standard of factor load greater than 0.5; each research variable has no negative measurement error, and the standard deviation is relatively small, lower than 0.05 ; the critical ratios are all greater than 3.29, and the parameter estimates all reach the significant level of $0.001(P<0.001$, represented by the ${ }^{* * *}$ symbol), indicating that each factor index has a strong explanatory power for the measurement model, and the basic fitness of the model is good.

5.4. Correlation Analysis and Discriminant Validity. It can be seen from Table 5 that the correlation coefficients between the variables are all lower than 0.7 , and there is no multicollinearity. The bold numbers are the square root of the AVE of the corresponding variables. The nonbold numbers are the correlation coefficients of the corresponding variables. The bold numbers are all greater than the absolute value of the nonbold numbers, indicating that the discriminant validity is better; that is, there is a certain degree of discrimination between variables.

\subsection{Inspection and Evaluation of Structural Model}

5.5.1. Testing of the Structural Model. Using AMOS22.0 to test the degree of fit of the conceptual model, the study obtains the index value of the degree of fit shown in Table 6 . It can be seen from Table 6 that the RMSEA (0.084) in the absolute fitting index is slightly greater than 0.08 and the PGFI (0.483) in the simple fitting index is slightly less than 0.5 , which does not meet the fitting requirements; the other indicators meet the fitting requirements. It can be seen that 
TABLE 2: Reliability test results of the observed variables and latent variables*.

\begin{tabular}{|c|c|c|c|}
\hline The name of the factor & Reliability ( ${ }^{*}$ coefficient $)$ & Composite reliability (CR) & Average variance extracted (AVE) values \\
\hline Elements of historical and cultural value & 0.855 & 0.893 & 0.584 \\
\hline Elements of architecture and space & 0.878 & 0.911 & 0.673 \\
\hline Elements of local service & 0.737 & 0.881 & 0.598 \\
\hline Elements of natural environment & 0.800 & 0.884 & 0.717 \\
\hline Place dependence & 0.907 & 0.931 & 0.729 \\
\hline Place attachment & 0.840 & 0.907 & 0.764 \\
\hline Place identity & 0.934 & 0.947 & 0.719 \\
\hline
\end{tabular}

* represents the measured value after eliminating the observed variables $X_{18}, X_{22}, X_{12}, X_{13}$, and $Y_{8}$.

TABLE 3: Overall measurement model indices.

\begin{tabular}{|c|c|c|c|c|c|c|c|c|c|}
\hline \multirow{2}{*}{$\begin{array}{l}\text { Index } \\
\text { Specific classification }\end{array}$} & \multicolumn{4}{|c|}{ Absolute fitting index } & \multicolumn{3}{|c|}{ Value-added fitting index } & \multicolumn{2}{|c|}{$\begin{array}{l}\text { Simple fitting } \\
\text { index }\end{array}$} \\
\hline & $\chi^{2 / \mathrm{df}}$ & GFI & RMR & RMSEA & NFI & TLI & CFI & PGFI & PNFI \\
\hline Judgment criteria & $<3$ & $>0.9$ & $<0.08$ & $<0.08$ & $>0.9$ & $>0.9$ & $>0.9$ & $>0.5$ & $>0.5$ \\
\hline Fitting results & $8.689^{*}$ & 0.966 & 0.029 & 0.082 & 0.958 & 0.941 & 0.962 & 0.452 & 0.616 \\
\hline Fitting evaluation & \multicolumn{4}{|c|}{ Good } & \multicolumn{3}{|c|}{ Very good } & \multicolumn{2}{|c|}{ Good } \\
\hline
\end{tabular}

*The sample size in this paper is $n=1137$, so the $\chi 2 / \mathrm{df}$ index is not referenced. Note: when the sample size is greater than 1,000 , the index has no reference significance [68].

TABLE 4: Estimation of path coefficients for measurement models.

\begin{tabular}{|c|c|c|c|c|c|c|c|c|c|c|c|}
\hline \multicolumn{3}{|c|}{$\begin{array}{l}\text { Relationship between potential variables and } \\
\text { observed variables }\end{array}$} & \multirow{2}{*}{$\begin{array}{c}\begin{array}{c}\text { Unstandardized } \\
\text { estimation }\end{array} \\
1\end{array}$} & \multirow[t]{2}{*}{ S.E. } & \multirow[t]{2}{*}{ C.R. } & \multirow[t]{2}{*}{$\mathrm{P}$} & \multirow{2}{*}{$\begin{array}{c}\begin{array}{c}\text { Standardized } \\
\text { estimation }\end{array} \\
0.791\end{array}$} & \multirow{2}{*}{$\begin{array}{l}\text { SMC } \\
0.626\end{array}$} & \multirow{2}{*}{$\begin{array}{c}\begin{array}{c}1- \\
\text { SMC }\end{array} \\
0.374\end{array}$} & \multirow[t]{2}{*}{$\mathrm{CR}$} & \multirow[t]{2}{*}{ AVE } \\
\hline $\begin{array}{l}\text { Elements of historical and } \\
\text { cultural value }\end{array}$ & $<---$ & Placeness & & & & & & & & & \\
\hline $\begin{array}{l}\text { Elements of architecture } \\
\text { and space }\end{array}$ & $<---$ & Placeness & 1.002 & 0.043 & 23.378 & $* * *$ & 0.780 & 0.608 & 0.392 & 0.809 & 0.517 \\
\hline $\begin{array}{l}\text { Elements of natural } \\
\text { environment }\end{array}$ & $<---$ & Placeness & 0.860 & 0.044 & 19.503 & $* * *$ & 0.626 & 0.392 & 0.608 & & \\
\hline Elements of local service & $<---$ & Placeness & 0.772 & 0.037 & 20.723 & $* * *$ & 0.666 & 0.444 & 0.556 & & \\
\hline Place identity & $<---$ & $\begin{array}{l}\text { Sense of } \\
\text { place }\end{array}$ & 1 & & & $* * *$ & 0.877 & 0.770 & 0.230 & & \\
\hline Place attachment & $<---$ & $\begin{array}{l}\text { Sense of } \\
\text { place }\end{array}$ & 0.777 & 0.026 & 30.180 & $* * *$ & 0.778 & 0.605 & 0.395 & 0.881 & 0.712 \\
\hline Place dependence & $<---$ & $\begin{array}{l}\text { Sense of } \\
\text { place }\end{array}$ & 0.935 & 0.028 & 33.612 & $* * *$ & 0.872 & 0.760 & 0.240 & & \\
\hline
\end{tabular}

${ }^{* * *}$ At the 0.001 level (2-tailed), the correlation is significant.

TABLE 5: Discriminant validity matrix.

\begin{tabular}{lccc}
\hline & Placeness & Sense of place & Satisfaction \\
\hline Placeness & $\mathbf{0 . 7 1 9}$ & & $\mathbf{0 . 8 4 4}$ \\
Sense of place & $.207^{* *}$ & $.446^{* *}$ & 1 \\
Satisfaction & $.413^{* *}$ & 1 \\
\hline
\end{tabular}

** At the 0.01 level (2-tailed), the correlation is significant.

the degree of fitting between the measurement model and the data is at a better level, the external quality of the model is good, and no further correction is needed.

5.5.2. Evaluation of the Structural Model. The software AMOS22.0 is used to evaluate the structural relationship between the latent variables of the initial conceptual model, and the specific results are shown in Table 7 . From Table 7 , the absolute value of the critical value (CR) of each coefficient is greater than 3.29 , and the parameter estimates are all up to 0.001 ( $P$ value is ${ }^{* * *}$, representing significant at the 0.001 level) significance level, that is, all passing the significance test. Among them, the standardized path coefficient of placeness and sense of place is 0.212 , indicating that the respondents' perception of placeness has a significant positive impact on the formation of sense of place; the standardized path coefficient of placeness and satisfaction is 0.366, indicating that the respondents' perception of placeness has a significant positive impact on their 


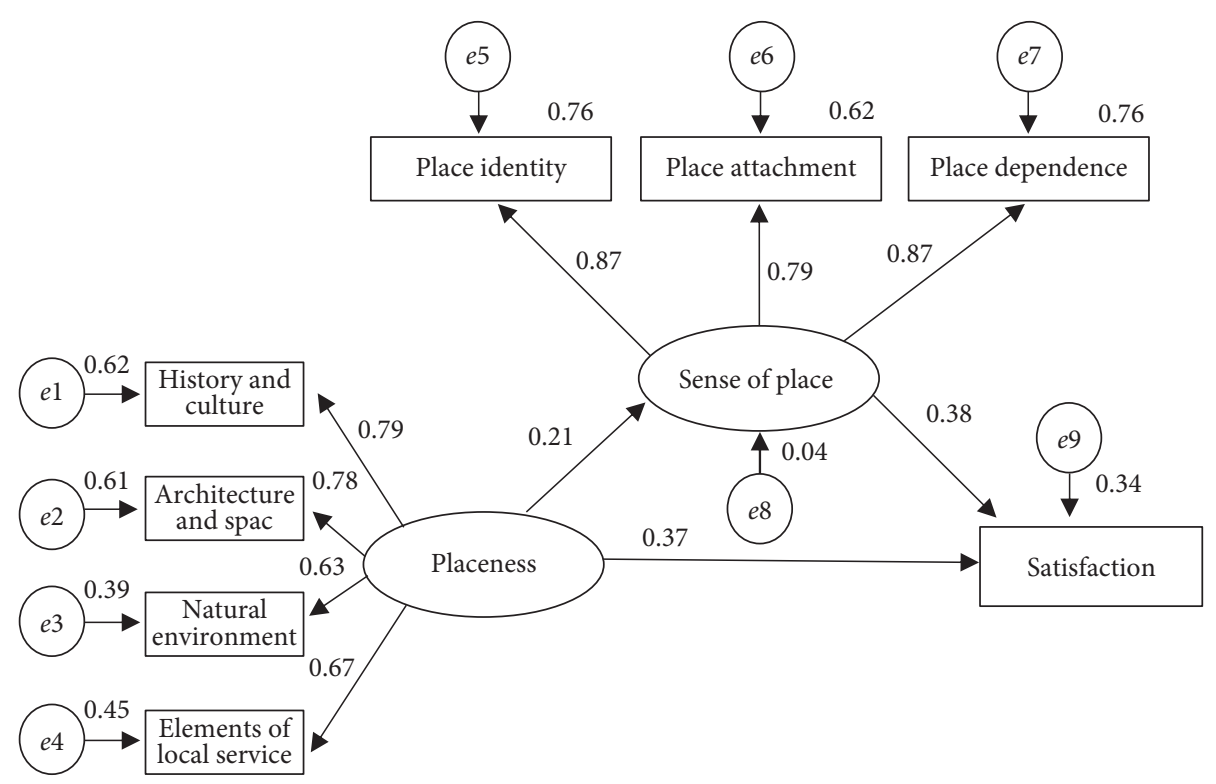

FIGURE 3: Ultimate structural equation modeling.

satisfaction; the standardized path coefficient between place and satisfaction is 0.382 , indicating that the sense of place formed by the survey has a significant positive impact on satisfaction. Through the comparison of the size of the path coefficient, it can be seen that the degree of influence of the respondents' sense of place on satisfaction is greater than the influence of their perception of placeness on satisfaction (Figure 3).

5.6. Analysis of Mediating Effect. This study uses the biascorrected percentile bootstrap method to test the significance of the mediating effect. First, the study uses the method of repeated random sampling to extract 2,000 bootstrap samples from the original data $(N=1137)$, and then fit the model based on these samples, generate and save the estimated value of 1,000 mediation effects, from an approximate sampling distribution, and calculate the average path value of the mediation effect, and these effect values are sorted by numerical value. Finally, the study uses the 2.5th percentile and the 97.5th percentile to estimate the 95\% confidence interval of the mediation effect. If the $95 \%$ confidence interval of these path coefficients does not include 0 , it indicates that the mediating effect is significant. Then, look at whether the confidence interval (or significance) of the standardized direct effect contains 0 , if it contains 0 (that is, it is not significant), it is full mediation; otherwise, it is partial mediation.

It can be seen from Table 8 that the 95\% confidence interval of the indirect effect of placeness on satisfaction is $[0.049,0.115]$, which does not contain 0 , so the mediating effect is significant. The $95 \%$ confidence interval of the direct effect of placeness on satisfaction is [0.308, 0.427], which does not include 0 , so partial mediating effects are significant. The indirect effect value was 0.081 , while the direct effect value was 0.366 , and the total effect value was 0.447 . All passed the test of significance level (0.001). The ratio of indirect effect to total effect was 0.081/ $0.447=0.181$. That is to say, $18.1 \%$ of the variation was caused by the sense of place when placeness affected overall satisfaction.

It can be proved that the respondents' perception of placeness can not only directly affect satisfaction, but also form an indirect effect on satisfaction through the sense of place. The sense of place can be used as an intermediary variable for the influence of placeness on satisfaction.

5.7. Analysis of Moderating Effect. To test whether the constructed model has cross-group stability, this study uses the model to perform multiple-group path analysis with different identity type (resident or tourist) variables. If there is no significant difference, it means that the identity type variable has no effect on the model; if there is a significant difference, it means that the identity type variable has a moderating effect.

When the multiple-group structural equation model is running, Amos 22.0 sets five parameter restriction models, so the multiple-group model includes six models: unrestricted model, measurement weighted model, structure weighted model, structure covariance model, structure residual error model, and measurement residual model. Two judgments are required for multigroup analysis: whether each model is recognized and whether the recognized model meets the standard. If the sample data of each group is large, the chi-square value that limits the overall fitness statistics of the model should be used as one of the reference standards, and the overall judgment needs to be made from the fitness situation of each fitness statistics [69]. If there are more than two identified models that meet the standard, the optimal model needs to be judged based on AIC and ECVI. The model with the smallest value of AIC and ECVI is the best model. The overall fitness test results of the multiple-group model are 
TABLE 6: Structural equation model indices.

\begin{tabular}{lccccccccc}
\hline Index & \multicolumn{3}{c}{ Absolute fitting index } & & \multicolumn{2}{c}{ Value-added fitting index } & \multicolumn{2}{c}{ Simple fitting } \\
index
\end{tabular}

*The sample size in this paper is $n=1137$, so the $\chi 2 / \mathrm{df}$ index is not referenced. When the sample size is greater than 1,000 , this index has no reference significance [68].

TABle 7: Path coefficient estimation of the structural equation model.

\begin{tabular}{|c|c|c|c|c|c|c|c|}
\hline \multicolumn{3}{|c|}{$\begin{array}{l}\text { Path relationship among potential } \\
\text { variables }\end{array}$} & \multirow{2}{*}{$\begin{array}{c}\text { Unstandardized estimation } \\
0.286\end{array}$} & \multirow{2}{*}{$\begin{array}{c}\text { Standardized estimation } \\
0.212\end{array}$} & \multirow{2}{*}{$\begin{array}{c}\text { Standard error } \\
0.047\end{array}$} & \multirow{2}{*}{$\begin{array}{c}\text { Critical value } \\
6.102\end{array}$} & \multirow{2}{*}{$\frac{P \text { value }}{* * *}$} \\
\hline Sense of place & & Placeness & & & & & \\
\hline Satisfaction & $<---$ & Placeness & 0.573 & 0.366 & 0.047 & 12.263 & $* * *$ \\
\hline Satisfaction & $<---$ & Sense of place & 0.443 & 0.382 & 0.033 & 13.61 & $* * *$ \\
\hline
\end{tabular}

${ }^{* * *}$ At the 0.001 level (2-tailed), the correlation is significant.

TABLE 8: Bootstrap analysis for the significance test of mediation effect.

\begin{tabular}{|c|c|c|c|c|c|}
\hline & \multirow{2}{*}{ Effect value } & \multicolumn{2}{|c|}{ 95\% confidence interval } & \multirow{2}{*}{$P$} & \multirow{2}{*}{ Intermediary judgment } \\
\hline & & Lower limit & Upper limit & & \\
\hline Indirect effect & 0.081 & 0.049 & 0.115 & 0.001 & Intermediary existed \\
\hline Direct effect & 0.366 & 0.308 & 0.427 & 0.001 & Part of the intermediary \\
\hline Total effect & 0.447 & 0.388 & 0.506 & 0.001 & \\
\hline
\end{tabular}

TABLE 9: Multigroup modeling indicators comparison of the overall adaptation.

\begin{tabular}{|c|c|c|c|c|c|c|c|}
\hline $\begin{array}{l}\text { Test } \\
\text { statistic }\end{array}$ & $\begin{array}{c}\text { Reference } \\
\text { standard }\end{array}$ & $\begin{array}{l}\text { Unrestricted } \\
\text { model }\end{array}$ & $\begin{array}{c}\text { Measurement } \\
\text { weighting model }\end{array}$ & $\begin{array}{c}\text { Structure } \\
\text { weighted } \\
\text { model }\end{array}$ & $\begin{array}{c}\text { Structural } \\
\text { covariance } \\
\text { model }\end{array}$ & $\begin{array}{c}\text { Structural } \\
\text { residual model }\end{array}$ & $\begin{array}{l}\text { Measurement } \\
\text { residual model }\end{array}$ \\
\hline CMIN/DF & $<3$ & 4.282 & 4.429 & 5.617 & 5.526 & 5.524 & 7.506 \\
\hline $\mathrm{P}$ & $>0.05$ & $\leq 0.001$ & $\leq 0.001$ & $\leq 0.001$ & $\leq 0.001$ & $\leq 0.001$ & $\leq 0.001$ \\
\hline RMR & $<0.05$ & 0.023 & 0.030 & 0.061 & 0.059 & 0.068 & 0.073 \\
\hline RMSEA & $<0.05$ & 0.054 & 0.055 & 0.064 & 0.063 & 0.063 & 0.076 \\
\hline GFI & $>0.9$ & 0.968 & 0.960 & 0.951 & 0.951 & 0.950 & 0.923 \\
\hline NFI & $>0.9$ & 0.959 & 0.949 & 0.934 & 0.934 & 0.932 & 0.892 \\
\hline CFI & $>0.95$ & 0.968 & 0.960 & 0.945 & 0.945 & 0.944 & 0.905 \\
\hline PNFI & $>0.5$ & 0.617 & 0.729 & 0.734 & 0.750 & 0.766 & 0.860 \\
\hline PGFI & $>0.5$ & 0.484 & 0.574 & 0.581 & 0.594 & 0.607 & 0.692 \\
\hline AIC & $\begin{array}{l}\text { The smaller } \\
\text { the better }\end{array}$ & 226.148 & 248.449 & 303.159 & 302.676 & 306.109 & 441.309 \\
\hline ECVI & $\begin{array}{l}\text { The smaller } \\
\text { the better }\end{array}$ & 0.199 & 0.219 & 0.267 & 0.267 & 0.270 & 0.389 \\
\hline
\end{tabular}

shown in Table 9. Through the comparison and analysis of the fitness of the six hypothetical models, the multigroup model with identity type as moderator variables after comparison, the measurement weighted model is determined as the best model.

According to the model comparison in Table 10, there are significant differences between the unrestricted model and the restricted model. The $\mathrm{p}$ value was less than 0.05 , which passed the significance test. Therefore, there are significant differences in the models of different identity types, that is, identity types play a moderating role.

By sorting out the data calculation results, the estimation results of the multiple-group structural equation model of two different identity types are obtained, as shown in Table 11, and the specific path diagrams are shown in Figures 4 and 5 .

The analysis results of the multiple-group structural equation model show that in the path $\mathrm{H} 1$ of the positive influence of placeness on the sense of place, the influence of tourists and local residents is very significant $(P<0.001)$, and the influence effects of the two types of identity are quite different. Among them, the impact effect of tourists $(0.601)$ is greater than that of local residents (0.257). In the path $\mathrm{H} 2$ of the positive influence of placeness on satisfaction, the influence of tourists and local residents is very significant $(P<0.001)$, and the 
TABle 10: Comparison between unrestricted model and restricted model (measurement weighted model).

\begin{tabular}{lccccccc}
\hline Model & DF & CMIN & P & NFI Delta-1 & IFI Delta-2 & RFI rho-1 & TLI rho2 \\
\hline Measurement weights & 7 & 36.301 & 0.000 & 0.010 & 0.010 & 0.002 & 0.002 \\
\hline
\end{tabular}

TABLE 11: Estimated results of multigroup structural equation modeling based on tourists and residents.

\begin{tabular}{lcr}
\hline Route & Tourist & Respondents \\
\hline H1: sense of place<---placeness & $0.601^{* * *}$ & $0.257^{* * *}$ \\
H2: satisfaction $<--$ placeness & $0.289^{* * *}$ & $0.306^{* * *}$ \\
H3: satisfaction $<--$ sense of place & $0.454^{* * *}$ & $0.334^{* * *}$ \\
\hline
\end{tabular}

*denotes $P<0.05,{ }^{* *}$ denotes $P<0.01,{ }^{* * *}$ indicates $P<0.001$; paths $\mathrm{H} 1, \mathrm{H} 2$, and $\mathrm{H} 3$ are consistent with the previous hypothesis.

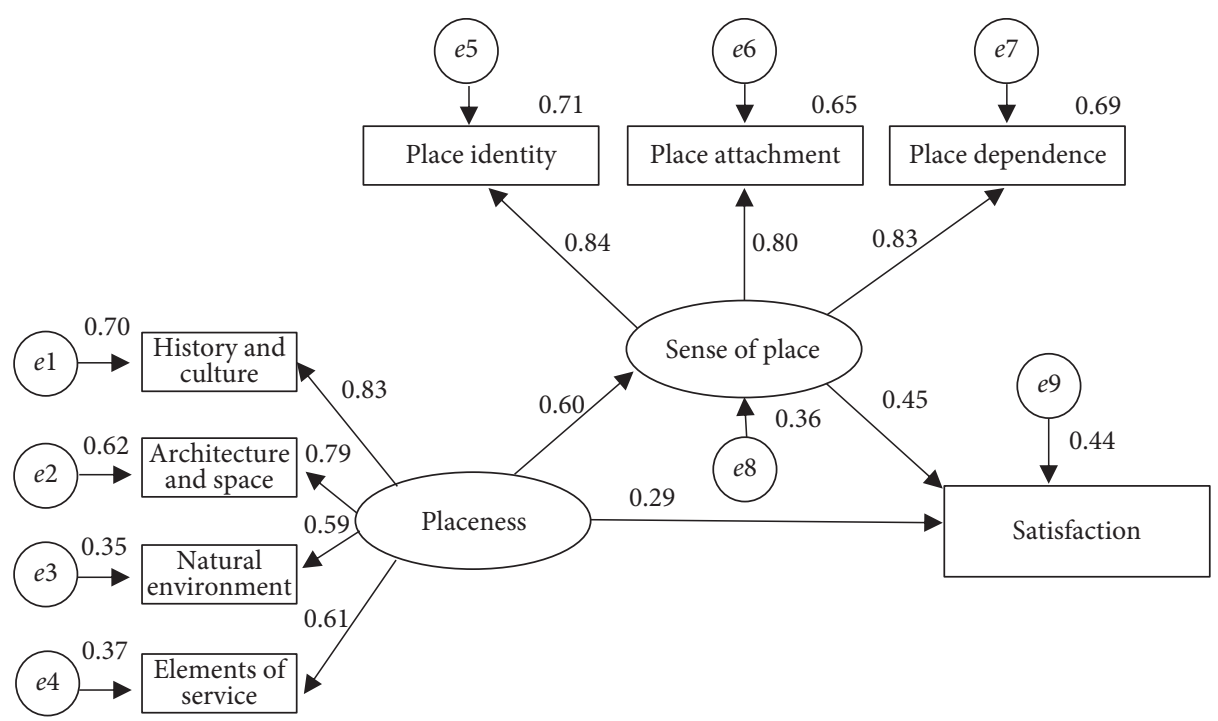

FIGURE 4: Standardized path coefficient of multi-group structural equation modeling for tourists.

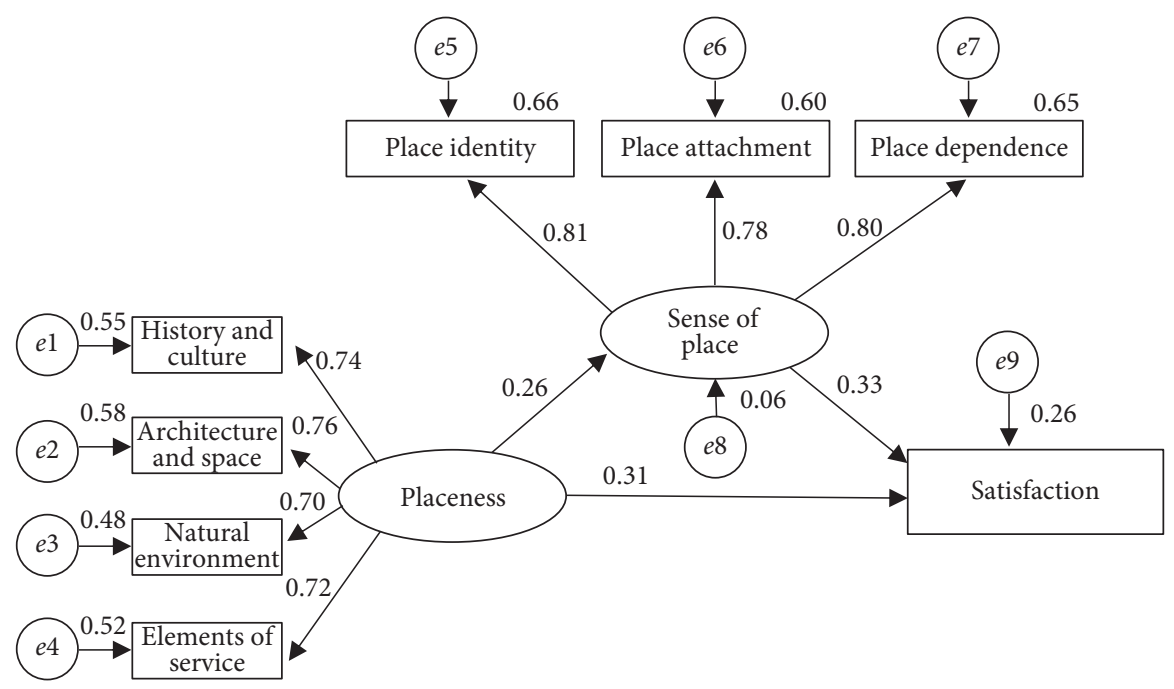

FIGURE 5: Standardized path coefficient of multi-group structural equation modeling for residents. 
difference is large. Among them, the influence of tourists $(0.289)$ is smaller than that of local residents $(0.306)$. In path $\mathrm{H} 3$, where the sense of place has a positive impact on satisfaction, the impact of tourists and local residents is very significant $(P<0.001)$, and there are large differences. Among them, the impact effect of tourists (0.454) is greater than that of local residents (0.334).

\section{Conclusion and Discussion}

6.1. Conclusion. In summary, based on relevant studies at home and abroad and previous studies, this paper constructs a causal model of placeness, sense of place, and satisfaction in the historical and cultural blocks in the old city of Beijing, and then, the model and research hypothesis proposed in this study were tested through the analysis of the covariance structure provided by AMOS. The test results show that all five hypotheses proposed in this study are valid.

First, direct effect: The two dimensions of place experience (placeness and sense of place) of residents and tourists in historical and cultural blocks of Beijing's old city have a remarkable positive impact on their satisfaction. Placeness has a significant positive impact on sense of place, hypothesis 1 is tenable; placeness has a significant positive impact on satisfaction, hypothesis 2 is tenable; sense of place has a significant positive impact on satisfaction, hypothesis is tenable. Moreover, the sense of place formed by the respondents has a slightly greater impact on satisfaction than placeness.

Second, indirect effect: Sense of place has a prominent mediating effect on the relationship between placeness and satisfaction. From the research results, we can see that placeness not only has a significant direct effect on satisfaction, but also has a significant indirect effect on satisfaction through sense of place.

Thirdly, when identity type is used as a moderating variable, the correlation strength among placeness, sense of place, and satisfaction will change significantly. The results show that the causalities of the three for residents and tourists are consistent, but the influence intensities are significantly different.

6.2. Discussion. This study aims to take Beijing's historical and cultural district as the object, organize the three variables of placeness, sense of place, and satisfaction into a model by the structural equation, build the causal model of placeness, sense of place, and satisfaction, and compare the differences of causal mechanism for residents and tourists. The following results are obtained:

Firstly, it eliminates the differences of causality between placeness and satisfaction and between sense of place and satisfaction based on regression analysis and other research methods and obtains the definite causality among placeness, sense of place, and satisfaction.

Secondly, it reveals that the influence mechanisms of residents' and tourists' sense of place and satisfaction in historical and cultural blocks originate from placeness. Placeness is the foundation, and sense of place is the intermediary variable, and they affect satisfaction jointly. However, in the age of globalization and modernization, the landscape of these blocks in various places gradually tends to be similar, and the historical authenticity and placeness are gradually lost. The results of this study show that improving the local characteristics of these blocks in the old city of Beijing and accelerating sense of place for residents and tourists are the core of improving the satisfaction.

Thirdly, it reveals the direct and indirect effects of placeness on satisfaction, and the effect intensity varies on residents and tourists. The results show that the residents' satisfaction with Beijing's historical and cultural blocks is more directly influenced by placeness and less by local emotional links. Tourists' satisfaction is rooted in the indirect influence of placeness, or the emotional connection between tourists and places. The authors think that this may be because the local characteristics of Beijing's historical and cultural blocks have not been effectively protected. Tourists conduct local experience activities in a particular way and time constraints. In the process of tourism, tourists form sense of place through mutual confirmation and stimulus of the on-the-spot feelings based on the objective elements and the memory and imagination before tourism, and then their satisfaction evaluations are affected. However, residents' living environment has changed from the original pure living environment into tourist destinations under tourism development. This change often disrupts residents' place dependence and place attachment, thus affecting the promotion effect of sense of place on satisfaction.

\section{Research Deficiency and Prospect}

Firstly, the research subject is not extensive enough. The development of a historical and cultural district involves a wide range of participants, including residents, tourists, business operators, developers, and local governments. Different subjects have different experiences and interests, as well as different perceptions of the place experience of historical and cultural blocks, resulting in different appeals and satisfaction. This study only focuses on residents and tourists, which has certain limitations. In the future, we can further expand research subjects and make a comparative study among multiple subjects, so as to more comprehensively reflect the local characteristics of historical and cultural districts and the place significance given by different subjects.

Secondly, the research variables can be further expanded. This study provides a basic research framework for the formation of place experience and its impact on the satisfaction of residents and tourists in historical and cultural blocks. Through the model analysis, it can be concluded that for different subjects, residents and tourists, the effects of placeness and sense of place on satisfaction are different. This shows that the formation of sense of place and satisfaction not only comes from placeness, but may also be affected by other variables. For example, Tang [67] thinks that the formation of sense of place is an evaluation process based on environmental perception combined with personal behavior goals, and the level of personal knowledge and 
experience is a vital factor in this evaluation process. Therefore, demographic factors affect the formation of sense of place in many cases. In addition, some studies have shown that there is a relationship between satisfaction and future behavior intention [70-73]. Therefore, variables such as demographic characteristics and place revisit intention can be added to expand the model variables in the future, so as to further reveal the complex mechanism between place experience and satisfaction.

\section{Data Availability}

All data used to support the findings of this study are available from the corresponding author upon request.

\section{Conflicts of Interest}

The authors declare that they have no conflicts of interest regarding the publication of this paper.

\section{Acknowledgments}

This study was supported by the Key Program of Beijing Social Science Foundation (19GLA001), the Major Program of the National Social Science Foundation of China (20ZDA086), and the General Program of the National Natural Science Foundation of China (52078006).

\section{References}

[1] G. Fleury-Bahi, M.-L. Félonneau, and D. Marchand, "Processes of place identification and residential satisfaction," Environment and Behavior, vol. 40, no. 5, pp. 669-682, 2008.

[2] Y. Tuan, "Place: an experiential perspective," Geographical Review, vol. 65, no. 2, pp. 151-165, 1975.

[3] E. Relph, Place and Placelessness, Pion, London, UK, 1976.

[4] J. D. Sime, "Creating places or designing spaces?" Journal of Environmental Psychology, vol. 6, no. 1, pp. 49-63, 1986.

[5] S. A. Shumaker and R. B. Taylor, Toward a Clarification of People-Place Relationships: A Model of Attachment to Place, Environmental Psychology: Directions and Perspectives, Praeger, New York, NY, USA, 1983.

[6] D. Hummon, Community Attachment: Local Sentiment and Sense of place, Place Attachment, New York press, New York, NY, USA, 1992.

[7] Y. Tuan, "Rootedness versus sense of place," Landscape, vol. 24, pp. 3-8, 1980.

[8] F. Steele, The Sense of Place, CBI Publishing Company Inc., Boston, MA, USA, 1981.

[9] E. H. Zube, J. L. Sell, and J. G. Taylor, "Landscape perception: research, application and theory," Landscape Planning, vol. 9, no. 1, pp. 1-33, 1982.

[10] T. C. Greene, Cognition and the Management of Place in the Nature and the Human Spirit, Venture Publishing, State College, PA, USA, 1996.

[11] B. S. Jorgensen and R. C. Stedman, "Sense of place as an attitude: lakeshore owners attitudes toward their properties," Journal of Environmental Psychology, vol. 21, no. 1, pp. 233248, 2001.

[12] H. M. Prohansky, A. K. Fabian, and R. Kaminoff, "Placeidentity: physical world socialization of the self," Journal of Environmental Psychology, vol. 3, no. 1, pp. 57-83, 1983.
[13] G. M. Breakwell, Coping with Threatened Identity, Methuen, London, UK, 1986.

[14] D. R. Williams and J. W. Roggenbuck, "Measuring place attachment: some preliminary results. Proceeding of NRPA symposium on leisure research," in Proceedings of the NRPA Symposium on Leisure Research, vol. 9, San Antonio, TX, USA, October 1989.

[15] D. R. Williams, M. E. Patterson, J. W. Roggenbuck, and A. E. Watson, "Beyond the commodity metaphor: examining emotional and symbolic attachment to place," Leisure Sciences, vol. 14, no. 1, pp. 29-46, 1992.

[16] M. V. Giuliani and R. Feldman, "Place attachment in a developmental and cultural context," Journal of Environmental Psychology, vol. 13, no. 3, pp. 267-274, 1993.

[17] K. S. Bricker and D. L. Kerstetter, "Level of specialization and place attachment: an Exploratory study of Whitewater Recreationists," Leisure Sciences, vol. 22, no. 4, pp. 233-257, 2000.

[18] K. De Bres and J. Davis, "Celebrating group and place identity: a case study of a new regional festival," Tourism Geographies, vol. 3, no. 3, pp. 326-337, 2001.

[19] K. S. Bricker and D. L. Kerstetter, "An interpretation of special place meanings whitewater recreationists attach to the south Fork of the American River," Tourism Geographies, vol. 4, no. 4, pp. 396-425, 2002.

[20] G. Kyle, A. Graefe, R. Manning, and J. Bacon, "An examination of the relationship between leisure activity involvement and place attachment among hikers along the appalachian trail," Journal of Leisure Research, vol. 35, no. 3, pp. 249-273, 2003.

[21] G. Kyle, A. Graefe, R. Manning, and J. Bacon, "Effects of place attachment on users' perceptions of social and environmental conditions in a natural setting," Journal of Environmental Psychology, vol. 24, no. 2, pp. 213-225, 2004.

[22] M. A. Abou-Shouk, N. Zoair, M. N. El-Barbary, and M. M. Hewedi, "Sense of place relationship with tourist satisfaction and intentional revisit: evidence from Egypt," International Journal of Tourism Research, vol. 20, no. 2, pp. 172-181, 2018.

[23] M. Lalli, "Urban-related identity: theory, measurement, and empirical findings," Journal of Environmental Psychology, vol. 12, no. 4, pp. 285-303, 1992.

[24] E. Relph, "Placeness, place, placelessness," 2019, http://www. placeness.com.

[25] Y. Xiao, Research on Regional Gene of Historical and Cultural Blocks Based on Tourist Satisfaction, Zhejiang University of technology and industry, Hangzhou, China, 2018.

[26] F. Wang, X. Huang, and X. Yu, "Tourist cognition of sense of place in tourism attractions," Acta Geographica Sinica, vol. 64, no. 10, pp. 1267-1277, 2009.

[27] F. Wang, L. Yan, X. Xiong, and B. Wu, "A study on tourist cognition of urban memory in historic sites: a case study of alley nanluogu historic site in beijing," Acta Geographica Sinica, vol. 67, no. 4, pp. 545-556, 2012.

[28] M. Zhang and F. Wang, "Research on the sense of place in the historical area of Beijing residents," Urban, vol. 218, no. 9, pp. 43-51, 2013.

[29] Z. Zhang and H. Duan, "Analysis on the relation mechanism between environmental locality and Tourists'Sense of place based on Amos7. 0 platform: a case study of xi'an daming palace national archaeological park," Tourism Science, vol. 28, no. 4, pp. 81-94, 2014.

[30] G. Gabriela, V. Aziliz, and V. B. Koenraad, "Place attachment and challenges of historic cities: a qualitative empirical study on heritage values in cuenca, Ecuador," Journal of Cultural 
Heritage Management and Sustainable Development, vol. 8, no. 3, pp. 387-399, 2018.

[31] A. Kusumowidagdo and D. K. Wardhani, "Investigating a sense of place at a historic commercial street corridor: visitor perception of social aspects," in Proceedings of the Cities' Identity through Architecture and Arts: Proceedings of the International Conference on Cities' Identity through Architecture and Arts (CITAA 2017), Routledge, Cairo, Egypt, May 2017.

[32] D. K. Wardhani and A. Kusumowidagdo, Authenticity of the Physical Environment that Influences a Sense of Place: A Qualitative Study at Ampel Street Corridor, Surabaya, Indonesia, Cities' Identity Through Architecture and Arts, Routledge, London, UK, 2018.

[33] D. G. Özkan and S. Yilmaz, "The effects of physical and social attributes of place on place attachment," Archnet-IJAR: International Journal of Architectural Research, vol. 13, no. 1, pp. 133-150, 2019.

[34] B. Nanzer, "Measuring sense of place: a scale for Michigan," Administrative Theory \& Praxis, vol. 26, no. 3, pp. 362-382, 2004.

[35] L. K. Harmon, H. C. Zinn, and M. Gleason, "Place identity, place dependence, and place- based affect: examining their relationship to participation in educational and interpretive programs at isle royale national park," in Proceedings of the People, Places, and Parks: Proceedings of the 2005 George Wright Society Conference on Parks, Protected Areas, and Cultural Sites, The George Wright Society, Hancock, MI, USA, August 2006.

[36] G. T. Kyle, A. J. Mowen, J. D. Absher, and M. E. Havitz, "Commitment to public leisure service providers: a conceptual and psychometric analysis," Journal of Leisure Research, vol. 38, no. 1, pp. 78-103, 2006.

[37] K. Deutsch and K. Goulias, Investigating the Impact of Sense of Place on Travel Behavior Using an Intercept Survey Methodology, University of California Transportation Center, UC Berkeley, Berkeley, CA, USA, 2009.

[38] S. Tapsuwan, Z. Leviston, and D. Tucker, "Community values and attitudes towards land use on the gnangara groundwater System: a sense of place study in perth, western Australia," Landscape and Urban Planning, vol. 100, no. 1-2, pp. 24-34, 2011.

[39] A. Yuksel, F. Yuksel, and Y. Bilim, "Destination attachment: effects on customer satisfaction and cognitive, affective and conative loyalty," Tourism Management, vol. 31, no. 2, pp. 274-284, 2010.

[40] Y. Yu, J. Tian, and J. Su, "A study of the relativity between place attachment and post-tour behavioral tendencies of visitors: taking value perception and satisfaction experience as intermediary variables," Tourism Science, vol. 24, no. 2, pp. 54-62,74, 2010.

[41] G. Prayag and C. Ryan, "Antecedents of tourists' loyalty to Mauritius," Journal of Travel Research, vol. 51, no. 3, pp. 342-356, 2012.

[42] H. Ramkissoon, L. D. G. Smith, and B. Weiler, "Relationships between place attachment, place satisfaction and pro-environmental behaviour in an Australian national park," Journal of Sustainable Tourism, vol. 21, no. 3, pp. 434-457, 2013 a.

[43] H. Ramkissoon, L. D. Graham Smith, and B. Weiler, "Testing the dimensionality of place attachment and its relationships with place satisfaction and pro-environmental behaviours: a structural equation modelling approach," Tourism Management, vol. 36, pp. 552-566, 2013 b.
[44] B. P. Kaltenborn, "Effects of sense of place on responses to environmental impacts," Applied Geography, vol. 18, no. 2, pp. 169-189, 1998.

[45] C. C. M. Adriaanse, "Measuring residential satisfaction: a residential environmental satisfaction scale (RESS)," Journal of Housing and the Built Environment, vol. 22, no. 3, pp. 287-304, 2007.

[46] F. Rojo Perez, G. Fernandez-Mayoralas Fernandez, E. Pozo Rivera, and J. Manuel Rojo Abuin, "Ageing in place: predictors of the residential satisfaction of elderly," Social Indicators Research, vol. 54, no. 2, pp. 173-208, 2001.

[47] D. W. Chapman and J. R. Lombard, "Determinants of neighborhood satisfaction in fee-based gated and nongated communities," Urban Affairs Review, vol. 41, no. 6, pp. 769-799, 2006.

[48] K. M. Smith, The Relationship between Residential Satisfaction, Sense of Community, Sense of Belonging and Sense of Place in a Western Australian Urban Planned Community, Edith Cowan University, Perth, Australia, 2011.

[49] X. Li, Research on Relantionship between Sense of Place of Inhabitants and Satisfaction of Inhabitants-A Case Study of LiJingmen Historical and Cultural Blocks of LuoYang, Jiangxi Normal University, Nanchang, China, 2018.

[50] D. Uzzell, E. Pol, and D. Badenas, "Place identification, social cohesion, and enviornmental sustainability," Environment and Behavior, vol. 34, no. 1, pp. 26-53, 2002.

[51] E. D. Brocato, Place Attachment: An Investigation of Environments and Outcomes in Service Context, University of Texas at Arlington, Arlington, TX, USA, 2006.

[52] K. Y. Lee and M. G. Jeong, "Residential environmental satisfaction, social capital, and place attachment: the case of Seoul, Korea," Journal of Housing and the Built Environment, vol. 36, no. 2, pp. 559-575, 2020.

[53] M. Bonnes, M. Bonaiuto, and A. P. Ercolani, "Crowding and residential satisfaction in the urban environment," Environment and Behavior, vol. 23, no. 5, pp. 531-552, 1991.

[54] M. Braubach, "Residential conditions and their impact on residential environment satisfaction and health: results of the who large analysis and review of european housing and health status (lares) study," International Journal of Environment and Pollution, vol. 30, no. 3/4, pp. 384-403, 2007.

[55] M. Aragonés and J. Aragones, "A theoretical and methodological approach to the study of residential satisfaction," Journal of Environmental Psychology, vol. 17, no. 1, pp. 47-57, 1997.

[56] J. Potter and R. Cantarero, "How does increasing population and diversity affect resident satisfaction? A small community case study," Environment and Behavior, vol. 38, no. 5, pp. 605-625, 2006.

[57] M. Bonaiuto, A. Aiello, M. Perugini, M. Bonnes, and A. P. Ercolani, "Multidimensional perception of residential environment quality and neighbourhood attachment in the urban environment," Journal of Environmental Psychology, vol. 19, no. 4, pp. 331-352, 1999.

[58] J. Bardo, "Dimensions of community satisfaction in a British new town," Multivariate Experimental Clinical Research, vol. 2, no. 3, pp. 129-134, 1976.

[59] M. Aragonés and J. Aragones, "Residential satisfaction in council housing," Journal of Environmental Psychology, vol. 10, no. 4, pp. 313-325, 1990.

[60] G. C. Galster and G. W. Hesser, "Residential satisfaction," Environment and Behavior, vol. 13, no. 6, pp. 735-758, 1981. 
[61] J. B. Hughey and J. W. Bardo, "The structure of community satisfaction in a southeastern American city," The Journal of Social Psychology, vol. 123, no. 1, pp. 91-99, 1984.

[62] M. Lu, "Analyzing migration decisionmaking: relationships between residential satisfaction, mobility intentions, and moving behavior," Environment and Planning A, vol. 30, no. 8, pp. 1473-1495, 1998.

[63] M. Lu, "Determinants of residential satisfaction: ordered logit vs. Regression models," Growth and Change, vol. 30, no. 2, pp. 264-287, 1999.

[64] D. Carro, S. Valera, and T. Vidal, "Perceived insecurity in the public space: personal, social and environmental variables," Quality \& Quantity, vol. 44, no. 2, pp. 303-314, 2010.

[65] D. Krešić, J. Mikulić, and K. Miličević, “The factor structure of tourist satisfaction at pilgrimage destinations: the case of Medjugorje," International Journal of tourism Research, vol. 15, no. 5, pp. 484-494, 2013.

[66] G. T. Kyle, A. Mowen, and M. Tarrant, "Linking place preferences with place meaning: an examination of the relationship between place motivation and place attachment," Journal of Environmental Psychology, vol. 24, no. 4, pp. 439-454, 2004.

[67] W. Tang, The Sense of Place in Tourism Destination, Social Science academic press, Beijing, China, 2013.

[68] Z. Wen, J. Hou, and M. Herbert, "Structural equation model test: fitting index and chi-square criterion," Acta Psychologica Sinica, vol. 36, no. 2, pp. 186-194, 2004.

[69] M. Wu, Questionnaire Statistical Analysis Practice-SPSS Operation and Application, Chongqing University Press, Chongqing, China, 2010.

[70] P. Kotler, D. Haider, and I. Rein, “There's no place like our place! the marketing of cities, regions, and nations," Public Management, vol. 76, pp. 15-18, 1994.

[71] M. Kozak and M. Rimmington, "Tourist satisfaction with Mallorca, Spain, as an off-season holiday destination," Journal of Travel Research, vol. 38, pp. 260-269, 2000.

[72] J. E. Bigné, M. I. Sánchez, and J. Sánchez, “Tourism image, evaluation variables and after-purchase behavior: inter-relationship," Tourism Management, vol. 22, no. 6, pp. 607-616, 2001.

[73] C. Chi and H. Qu, "Examining the structural relationships of destination image, tourist satisfaction and destination loyalty: an integrated approach," Tourism Management, vol. 29, pp. 624-636, 2008. 